\title{
Carbon Dioxide Water-bath Treatment Augments Peripheral Blood Flow through the Development of Angiogenesis
}

\begin{tabular}{|c|c|}
\hline Journal: & Canadian Journal of Physiology and Pharmacology \\
\hline Manuscript ID & cjpp-2017-0125.R1 \\
\hline Manuscript Type: & Article \\
\hline Date Submitted by the Author: & 28-Mar-2017 \\
\hline Complete List of Authors: & $\begin{array}{l}\text { Xu, Yan-Jun; Institute of Cardiovascular Sciences } \\
\text { Elimban, Vijayan; Institute of Cardiovascular Sciences, } \\
\text { Dhalla, Naranjan; Institute of Cardiovascular Sciences, }\end{array}$ \\
\hline $\begin{array}{r}\text { Is the invited manuscript for } \\
\text { consideration in a Special } \\
\text { Issue?: }\end{array}$ & IACS Sherbrooke 2016 special issue Part 1 \\
\hline Keyword: & $\begin{array}{l}\mathrm{CO}<\text { sub }></ \text { sub }>2<\text { sub }></ \text { sub }>\text { water-bath therapy, peripheral artery } \\
\text { disease, angiogenesis, vascular blood flow, oxidative stress }\end{array}$ \\
\hline
\end{tabular}




\title{
Carbon Dioxide Water-bath Treatment Augments
}

\section{Peripheral Blood Flow through the Development of Angiogenesis}

\author{
Yan-Jun Xu, Vijayan Elimban, and Naranjan S. Dhalla \\ Institute of Cardiovascular Sciences, St. Boniface Hospital Albrechtsen Research Centre, \\ Department of Physiology and Pathophysiology, Max Rady College of Medicine, Rady \\ Faculty of Health Sciences, University of Manitoba, Winnipeg, Manitoba, Canada
}

Short Title: $\mathrm{CO}_{2}$-induced Angiogenesis and Peripheral Blood Flow

\section{$\underline{\text { Address for Correspondence }}$}

Dr. Vijayan Elimban

Institute of Cardiovascular Sciences

St. Boniface Hospital Albrechtsen Research Centre

351 Tache Avenue

Winnipeg, MB, R2H 2A6, Canada

Telephone: 204-235-3412

E-mail: velimban@sbrc.ca 


\begin{abstract}
In this study, we investigated the effects of $\mathrm{CO}_{2}$ water-bath therapy on blood flow and angiogenesis in the ischemic hind limb as well as some plasma angiogenic factors in peripheral ischemic model. The hind limb ischemia was induced by occluding the femoral artery for 2 weeks in rats and treated with or without $\mathrm{CO}_{2}$ water-bath therapy at $37^{\circ} \mathrm{C}$ for 4 weeks $(20 \mathrm{~min}$ treatment everyday for 5 days per week). The peak blood flow as well as minimal and mean blood flow in the ischemic skeletal muscle were markedly increased by the $\mathrm{CO}_{2}$ water-bath therapy. This increase in blood flow was associated with development of angiogenesis in the muscle as well as reduction in the ischemia-induced increase in plasma malondialdehyde levels. Although plasma vascular endothelial growth factor and nitric oxide levels were increased in animals with peripheral ischemia, the changes in these biomarkers were not affected by $\mathrm{CO}_{2}$ water-bath therapy. These results suggest that augmentation of blood flow in the ischemic hind limb by $\mathrm{CO}_{2}$ water-bath therapy may be due to the development of angiogenesis and reduction in oxidative stress.
\end{abstract}

Keywords: $\mathrm{CO}_{2}$ water-bath therapy; peripheral artery disease; angiogenesis; vascular blood flow; oxidative stress 


\section{Introduction}

Peripheral artery disease, a major health hazard worldwide, is normally associated with obstruction of blood supply to the limb mainly as a consequence of atherosclerosis and thrombosis leading to the development of skeletal muscle ischemia (Dhalla et al. 2017; Kehler et al. 2013; Krishna et al. 2015; Norgren et al. 2007; Serano Hernando and Conejero 2007). Although a wide variety of defects for the production of different growth factors and various hormones, abnormalities in the function of endothelium and alterations in the vascular smooth muscle have been suggested to be intimately involved in the pathogenesis of peripheral artery disease (Carmaliet and Jain 2011; Dhalla et al. 2017; Krishna et al. 2015), the exact mechanisms of muscle dysfunction in the disease are not fully understood. Likewise, in spite of the availability of several surgical and medical interventions for the treatment of peripheral artery disease (Dhalla et al. 2017; Egginton et al. 2008; Li et al. 1998; Norgren et al. 2007; Potente et al. 2011; Serrano Hernando and Conjero 2007; Singla and Mehta 2013), none of the currently used therapies are satisfactory. Accordingly, it is of utmost importance that some new strategies be developed for improving the quality of life in patients suffering from peripheral artery disease.

Recently, some studies have been initiated for investigating the effects of stem cells and other cell therapy for improving blood flow in the ischemic limb (Botham et al. 2013; Cooke and Lasardo 2015; Raval and Losardo 2013). Furthermore, exercise training has been shown to induce collateral circulation for increasing the blood supply and maintaining the function of the ischemic muscle (Hoier et al. 2010; Kehler et al. 2013; Milkiewicz et al. 2005; Schirmer et al. 2015). In addition, both clinical and experimental investigations have indicated the beneficial effects of $\mathrm{CO}_{2}$ therapy for promoting the blood flow to the ischemic limb in peripheral artery 
disease (Dogliotti et al. 2011; Finzgar et al. 2015; Hartmann et al. 1997a, 1997b; Irie et al. 2005; Izumi et al. 2015; Nishimura et al. 2002; Pagourelias et al. 2011). However, extensive research work is needed to understand the mechanisms of $\mathrm{CO}_{2}$-induced increase in blood flow in the ischemic skeletal muscle. In view of the development of angiogenesis in the skeletal muscle in response to ischemia (Carmeliet 2003; Carmeliet and Jain 2011; Hudlicka et al. 1992; Limbourg et al. 2009; Lloyd et al. 2001; Olfert et al. 2016), this study was undertaken to examine if the increase in blood flow in the ischemic limb due to $\mathrm{CO}_{2}$ therapy is associated with the occurrence of angiogenesis. Furthermore, some of the angiogenic factors as well as plasma lipids were measured to test if any of these parameters could serve as biomarkers for identifying the beneficial effects of $\mathrm{CO}_{2}$ therapy in peripheral artery disease.

\section{Methods:}

Femoral artery ligation: The protocol and experimental design for the use of animals in this study were approved by the University of Manitoba Animal Care Committee according to the guidelines of the Canadian Council on Animal Care and the Guide to the Care and Use of Laboratory Animals. Male rats weighing 200-250g were anesthetized with $1-5 \%$ isoflurane in oxygen at a flow rate of $2 \mathrm{~L} / \mathrm{min}$. The surgical site was shaved and treated with a topical antiseptic, buprenorphine (Shao et al. 2005). Through a small incision on the medial aspect of the left thigh, femoral artery was isolated and completely occluded by ligation with 3-0 surgical silk approximately $5 \mathrm{~mm}$ distal to the inguinal ligament (Lloyd et al. 2001). The wound was closed with suture/clips, and the animals were allowed to recover in their cages. These animals with hind leg ischemia but with no infection at the surgical site after 2 weeks were used for experiments.

$\mathbf{C O}_{2}$-rich water-bath therapy: Two weeks after the surgery, when the surgical wound was 
completely healed, the ischemic animals were exposed to either $\mathrm{CO}_{2}$-enriched water-bath or water-bath without $\mathrm{CO}_{2}$ mixing at $37^{\circ} \mathrm{C}$ for 20 min everyday ( 5 days per week) for 4 weeks. It is pointed out that other investigators have also used 4 weeks duration for $\mathrm{CO}_{2}$ water-bath therapy (Irie et al. 2005; Izumi et al. 2015). The $\mathrm{CO}_{2}$-rich water was prepared by mixing $\mathrm{CO}_{2}$ in tap water using Carbothera, a therapeutic footbath unit (Mitsubishi Rayon Engineering, Tokyo, Japan) containing a multi-layered composite hollow-fiber membrane (Nishimura et al. 2002). The $\mathrm{CO}_{2}$ concentration was maintained at 1,000-12000 ppm (Figure 1A) throughout the bathing. Two groups of animals were kept in a Plexiglas plastic rat restrainer and the bottom portion including the hind limb was immersed in the water-bath at $37^{\circ} \mathrm{C}$ in a slant position. For one group (ischemic $-\mathrm{CO}_{2}$ ), the animals were exposed to water-bath without mixing $\mathrm{CO}_{2}$ whereas for the other group (ischemic $+\mathrm{CO}_{2}$ ), the animals were exposed to water-bath enriched with $\mathrm{CO}_{2}$. Two other groups of animals, one without and another with femoral artery ischemia were kept in cages with no water-bath treatment, served as controls. The experimental design for this study is depicted in Figure 1B. At the end of 4 week treatment, the animals were sacrificed under anesthesia (ketamine/xylazine; 90/9 mg/kg). Blood was collected from the abdominal aorta; serum was separated and used for biochemical analysis. The left leg skeletal muscle was collected and stored at $-70^{\circ} \mathrm{C}$ for analysis.

Blood flow measurements: Blood flow to the left leg skeletal muscle was measured before and immediately after femoral artery ligation as well as at 4 weeks after $\mathrm{CO}_{2}$-rich water-bath treatment using a Pulse Wave Doppler System (Indus Instruments, Webster, Texas, USA) (Hartley et al. 2011; Reddy et al. 2009). Rats were anesthetized with inhaled isoflurane (1\% in $\mathrm{O}_{2}$ ) and fixed in a supine position on the temperature-controlled ECG board (THM100, Indus Instruments, Webster, Texas, USA). Body temperature was maintained at $37^{\circ} \mathrm{C}$. Blood flow 
velocity was recorded using a 20-MHz pulsed Doppler probe at the level of femoral artery. Data were analyzed using an Indus Instruments Doppler Signal Processing Workstation. Heart rate and R-R interval were calculated using the Doppler spectrogram analysis software.

Tissue staining and angiogenesis: A cross section of skeletal muscle tissue just above the femoral artery ligation was fixed with $10 \%$ formalin for $24-48 \mathrm{~h}$ and processed after paraffin embedding using standard protocol (Feldman and Wolfe 2014; Fischer et al. 2008; Limbourg et al. 2009). About 10-15 sections of $5 \mu \mathrm{m}$ thickness each were taken using a Shandon, Finesse 325 microtome (Thermo Electron Corporation, Hampshire, UK). All tissue sections were stained with hematoxylin and eosin and observed under light microscope. Capillaries were visualized from images taken using Image ProPlus Digital System (Media Cybernetics, Rockville, MD, USA) (Garg and Mehrotra 2014). The quantitative analysis of angiogenesis was performed in a blinded manner. Although the area examined in all four groups was not the same, the data have been presented per tissue section.

Biochemical analysis: Serum analysis was performed on the Roche Cobas 6000 analyzer (Roche Diagnostics GmbH, Mannheim, Germany) using original Roche reagents. Cholesterol, triglycerides, and high density lipoproteins (HDL) were enzymatic-colorimetric assays. Glucose was run on a hexokinase UV method. Creatine kinase (CK) was determined using $\mathrm{N}$-acetyl cysteine activated UV assay. Vascular endothelial growth factor (VEGF) (Sigma-Aldrich, St. Louis, MO, USA), tumor necrosis factor-alpha (TNF- $\alpha$ ) (R\&D Systems, Minneapolis, MN, USA), nitric oxide (NO) (Enzo Life Science, Farmingdale, NY, USA), and malondialdehyde (MDA) (ZeptoMetrix, Buffalo, NY, USA) were measured using appropriate ELISA kits.

Statistical analysis: All values are expressed as mean \pm SE. The statistical analysis was carried out by using the Microcal Origin Version 6 (Microcal Software Inc., Northampton, MA, USA). 
One-way ANOVA analysis was used; the comparison of mean values of two groups was performed by Student's $t$-test and $P$ values less than 0.05 were considered to be significantly different.

\section{Results}

As shown in Figure 1 for the experimental protocol, ischemia in the hind leg of normal rats was induced by ligating the femoral artery for 2 weeks and thereafter these animals were subjected to water-bath treatment for 4 weeks with (ischemic $+\mathrm{CO}_{2}$ group) or without (ischemic - $\mathrm{CO}_{2}$ group) mixing $\mathrm{CO}_{2}$. No water-bath treatment was carried out for normal rats with (ischemic control group) or without (control group) peripheral ischemia. The electrocardiographic assessment of animals showed that for both heart rates and R-R intervals there were no significant differences among control, ischemia control, ischemic $-\mathrm{CO}_{2}$ group, and ischemic $+\mathrm{CO}_{2}$ groups (Table 1). Furthermore, values for plasma creatine kinase level (Table 1) as well as for plasma cholesterol, high density lipoproteins and glucose levels (Table 2) were similar among all four groups. Although plasma triglyceride level in ischemic control and ischemic $-\mathrm{CO}_{2}$ groups was significantly lower than in the control groups, these values were not different from that in the ischemic $+\mathrm{CO}_{2}$ group (Table 2).

The examination of peripheral blood flow by the Pulse Wave Doppler System in the hind legs of all animals revealed a marked depression for the peak blood flow, minimal blood flow and mean blood values in the ischemic control or ischemic $-\mathrm{CO}_{2}$ group in comparison to the control group (Figure 2). However, the blood flow in the ischemic animals was significantly improved upon $\mathrm{CO}_{2}$ water-bath therapy (ischemic $+\mathrm{CO}_{2}$ group) (Figure 2). It should be mentioned that no blood flow was detected in the hind limb immediately after the femoral artery 
ligation indicating that the degree of ischemia in different groups of animals was comparable. The histological evaluation revealed markedly higher magnitude of angiogenesis in the hind leg skeletal muscle upon $\mathrm{CO}_{2}$ water-bath treatment (ischemic $+\mathrm{CO}_{2}$ group) in comparison to other groups (Figure 3). It may also be noted that the peripheral ischemia with or without water-bath treatment did not produce any significant effect on the magnitude of angiogenesis in comparison to the control group (Figure 3).

In order to investigate if the improvement in peripheral blood by $\mathrm{CO}_{2}$ water-bath therapy was associated with any changes in some biomarkers, the concentrations of different angiogenic factors in plasma from all the four groups of animals was measured. The data in Figure 4 indicate that, unlike TNF- $\alpha$, the levels of plasma VEGF, NO and MDA were elevated in the ischemic control, ischemic $-\mathrm{CO}_{2}$ and ischemic $+\mathrm{CO}_{2}$ groups in comparison to the control group. The $\mathrm{CO}_{2}$ water-bath treatment did not affect the elevated plasma levels of VEGF and NO in the ischemic $-\mathrm{CO}_{2}$ group but the elevated plasma levels were significantly decreased in the ischemic $+\mathrm{CO}_{2}$ group.

\section{Discussion}

In this study we have demonstrated that $\mathrm{CO}_{2}$ water-bath therapy improves the peak blood flow, minimal blood flow and mean blood flow in the ischemic hind leg of rats. These observations are consistent with earlier reports showing increase in blood flow in the ischemic limb upon treatment with $\mathrm{CO}_{2}$ (Finzgar et al. 2015; Hartmann et al. 1997a; Irie et al. 2005; Izumi et al. 2015; Nishimura et al. 2002). Although $\mathrm{CO}_{2}$ water-bath therapy has been suggested to produce inhibition of the sympathetic activity or activation of the parasympathetic activity (Hashimoto and Yamamoto 2004; Sato et al. 2009), it is highly unlikely that the increased 
peripheral blood flow observed in our study is due to the involvement of these mechanisms because no changes in heart rate, $\mathrm{R}-\mathrm{R}$ intervals or plasma creatine kinase levels were observed upon therapy with $\mathrm{CO}_{2}$ water-bath. Furthermore, alterations in blood viscosity, membrane permeability and muscle metabolism (Dhalla et al. 2017) cannot explain the improved blood in the limb because no significant changes in plasma cholesterol, low density lipoprotein, triglyceride and glucose levels were seen due to $\mathrm{CO}_{2}$ water-bath treatment. On the other hand, since the elevated plasma level of MDA, a well known index of oxidative stress, in the ischemic animals was depressed by the $\mathrm{CO}_{2}$ water-bath therapy, it is suggested that the observed increase in peripheral blood flow may be related to the reduction of oxidative stress in the $\mathrm{CO}_{2}$-treated animals. It is pointed out that Dogliotti et al. (2011) have shown a depression of free radical release and elevation of the total antioxidant status upon immersion of lower legs of patients with peripheral occlusive disease in $\mathrm{CO}_{2}$-enriched water. In fact, $\mathrm{CO}_{2}$ has been found to be a potent inhibitor for the generation of reactive oxygen species by different types of cells (Bolevich et al. 2016).

It is well known that $\mathrm{CO}_{2}$ is a powerful vasodilator and has been shown to increase blood flow (Ito et al. 1989; Nishimura et al. 2002); however, it is difficult to assess the contribution of the direct vasodilatory effect in promoting the increase in blood flow under chronic conditions of $\mathrm{CO}_{2}$ water-bath therapy. On the other hand, this study has shown that the magnitude of angiogenesis in the hind limb skeletal muscle was markedly increased due to $\mathrm{CO}_{2}$ water-bath therapy. Such an increase in the degree of angiogenesis can be taken to suggest that the observed increase in peripheral blood flow in the ischemic limb upon $\mathrm{CO}_{2}$ water-bath therapy may be mainly due to the development of angiogenesis. In this regard, it is pointed out that exercise training has also been reported to promote blood flow and induce angiogenesis in the peripheral 
artery disease (Kehler et al. 2013; Schirmer et al. 2015). Since the development of angiogenesis is considered to have different therapeutic implications by promoting blood supply in several diseased organs (Carmeliet and Jain 2011; Potente et al. 2011), the induction of angiogenesis by $\mathrm{CO}_{2}$ water-bath treatment can be seen to form the basis of therapy for the peripheral artery disease. However, the involvement of several angiogenic factors in $\mathrm{CO}_{2}$-induced angiogenesis in the ischemic limb is not readily apparent because the plasma levels of VEGF, TNF- $\alpha$ and NO, which are known to promote angiogenesis (Dhalla et al. 2017; Hoier et al. 2010; Lloyd et al. 2001; Milkiewicz et al. 2005) were not augmented by the $\mathrm{CO}_{2}$ water-bath therapy. Such results may be due to the fact that these angiogenic factors were already elevated to maximal levels in animals with peripheral ischemia at the time of determination or these markers became increased during the early periods of $\mathrm{CO}_{2}$ water-bath therapy. Nonetheless, from the results presented in this study, it is evident that the improvement in blood flow in the ischemic limb may be due to the development of angiogenesis in the skeletal muscle. Our preliminary experiments have revealed no increase in blood flow or magnitude of angiogenesis in hind limb of control animals upon treatment with $\mathrm{CO}_{2}$-enriched water-bath.

Appearance of collateral blood vessels upon the obstruction of blood flow in the hind limb is considered to be an adaptive response to ischemia/hypoxia for maintaining the skeletal muscle function (Dhalla et al. 2017; Irie et al. 2005; Krishna et al. 2015; Serrano Hernando and Conejero 2007; Yang et al. 2009). Such a response has been shown to be a consequence mainly due to the production of hypoxia-inducible factor and formation of VEGF, NO, cytokines and other growth factors in the ischemic limb (Carmeliet and Jain 2011; Dhalla et al. 2017; Irie et al. 2005; Lloyd et al. 2001). In this study, we have observed that ligation of the femoral artery resulted in no blood flow immediately but thereafter in 6 weeks only a small amount of blood 
flow was detected in the hind limb. This was not associated with any increase in the magnitude of angiogenesis in the ischemic limb; however, a marked increase in the plasma levels of both VEGF and NO, unlike TNF- $\alpha$, was evident in animals with peripheral ischemia. Thus it appears that a small amount of blood flow in the ischemic limb may not be sufficient to maintain the skeletal muscle function leading to the development of peripheral artery disease. It is pointed out that we did not determine the time-course of changes in plasma TNF- $\alpha$ levels upon the induction of peripheral ischemia or during early periods of starting $\mathrm{CO}_{2}$ water-bath therapy. Thus some caution should be exercised while interpreting the data regarding the effect of $\mathrm{CO}_{2}$ therapy on this angiogenic factor.

The marked depression in blood flow in the ischemic limb may also be due to the occurrence of oxidative stress in the skeletal muscle because the plasma level of MDA was markedly elevated in the animals with peripheral ischemia. This view is consistent with marked increase in the magnitude of angiogenesis and blood flow as well as a reduction in the plasma MDA level upon $\mathrm{CO}_{2}$ water-bath treatment of patients with peripheral arterial disease (Dogliotti et al. 2011). Furthermore, the plasma level of Ox-LDL, another marker of oxidative stress, was also found to be reduced in ischemic diabetic rats upon $\mathrm{CO}_{2}$ water-bath therapy (Dhalla and Elimban 2017). Thus reduction in the occurrence of oxidative stress and increase in the development of angiogenesis by $\mathrm{CO}_{2}$ water-bath treatment may be important mechanisms for its beneficial effects in the peripheral artery disease. It is pointed out that oxidative stress at low levels or during the early period of its development is considered to exert beneficial effects through the activation of redox sensitive alterations in the cell whereas excessive or chronic oxidative stress is known to produce cellular damage (Tappia et al. 2006). It is likely that reduction in the development of oxidative stress by $\mathrm{CO}_{2}$ water-bath therapy may also increase 
the peripheral blood flow through the activation of some redox-sensitive signal transduction mechanisms in the ischemic limb. These events involving the reduction in oxidative stress and the development of angiogenesis leading to increased blood flow in the ischemic limb upon $\mathrm{CO}_{2}$ water-bath therapy are illustrated in Figure 5.

\section{Acknowledgements}

The infrastructural support was provided by the St. Boniface Hospital Research Foundation, Winnipeg, Canada.

\section{Conflict of Interest}

The financial support for this study was provided by a grant from the Mitsubishi Rayon Cleansui Co., Ltd., Tokyo, Japan. This is to declare that Y.-J. Xu, V. Elimban and N.S. Dhalla had no conflict of interest.

\section{References}

Bolevich, S., Kogan, A.H., Zivkovic, V., Djuric, D., Novikov, A.A., Vorobyev, S.I., and Jakovljevic, V. 2016. Protective role of carbon dioxide $\left(\mathrm{CO}_{2}\right)$ in generation of reactive oxygen species. Mol. Cell. Biochem. 411: 317-330.

Botham, C.M., Bennett, W.L, and Cooke, J.P. 2013. Clinical trials of adult stem cell therapy for peripheral artery disease. Mehodist Debakey Cardiovasc. J. 9: 201-205.

Carmeliet, P. 2003. Angiogenesis in health and disease. Nat. Med. 9: 653-660.

Carmeliet, P., and Jain, R.K. 2011. Molecular mechanisms and clinical applications of angiogenesis. Nature, 473: 298-307.

Cooke, J.P., and Losardo, D.W. 2015. Modulating the vascular response to limb ischemia: 
Angiogenic and cell therapies. Circ. Res. 116: 1561-1578.

Dhalla, N.S., Camargo, R.O., Elimban, V., Dhadial, R.S., and Xu, Y.-J. 2017. Role of skeletal muscle angiogenesis in peripheral artery disease. In Therapeutic Implications of Angiogenesis. Edited by J.L. Mehta, P. Mathur and N.S. Dhalla. Springer Nature, Switzerland, in press.

Dhalla, N.S. and Elimban, V. 2017. $\mathrm{CO}_{2}$ water bath therapy promotes blood flow and angiogenesis in diabetes with peripheral ischemia. In Program of the $9^{\text {th }}$ International Conference of the International Academy of Cardiovascular Sciences, Delhi, pp. 33

Dogliotti, G., Galliera, E., Iorio, E., De Bernardi Di Valserra, M., Solimene, U., and Corsi, M.M. 2011. Effect of immersion in $\mathrm{CO}_{2}$-enriched water on free radical release and total antioxidant status in peripheral arterial occlusive disease. Int. Angiol. 30: 12-17.

Egginton, S. 2008. Invited review: Activity-induced angiogenesis. Pflugers Arch. 457: 963-977.

Feldman, A.T., and Wolfe, D. 2014. Tissue processing and hematoxylin and eosin staining. Methods Mol. Biol. 1180: 31-43.

Finzgar, M., Melik, Z., and Cankar, K. 2015. Effect of transcutaneous application of gaseous carbon dioxide on cutaneous microcirculation. Clin. Hemorheol. Microcirc. 60: 423-435.

Fischer, A.H., Jacobson, K.A., Rose, J., and Zeller, R. 2008. Hematoxylin and eosin staining of tissue and cell sections. CSH Protoc. May 1;2008:pdb.prot4986. doi: 10.1101/pdb.prot4986.

Garg, N., and Mehrotra, R. 2014. Morphometric analysis of epithelial thickness and blood vessels in different grades of oral submucous fibrosis. Malaysian J. Pathol. 36: 189-193.

Hartley, C.L., Reddy, A.K., Madala, S., Entman, M.L., Michael, L.H., and Taffet, G.E. 2011. Doppler velocity measurements from large and small arteries of mice. Am. J. Physiol. Heart Circ. Physiol. 301: H269-H278. 
Hartmann, B.R., Bassenge, E., and Pittler, M. 1997a. Effect of carbon dioxide-enriched water and fresh water on the cutaneous microcirculation and oxygen tension in the skin of the foot. Angiology, 48: 337-343.

Hartmann, B.R., Bassenge, E., and Hartmann, M. 1997b. Effects of serial percutaneous application of carbon dioxide in intermittent claudication: Results of a controlled trial. Angiology, 48: 957-963.

Hashimoto, M., and Yamamoto, N. 2004. Decrease in heart rates by artificial $\mathrm{CO}_{2}$ hot spring bathing is inhibited by beta1-adrenoceptor blockade in anesthetized rats. J. Appl. Physiol. 96: 226-232.

Hoier, B., Olsen, K., Nyberg, M. Bangsbo, J., and Hellsten, Y. 2010. Contraction-induced secretion of VEGF from skeletal muscle cells is mediated by adenosine. Am. J. Physiol. Heart Circ. Physiol. 299: H857-H862.

Hudlicka, O., Brown, M., and Egginton, S. 1992. Angiogenesis in skeletal and cardiac muscle. Physiol. Rev. 72: 369-417.

Irie, H., Tatsumi, T., Takamiya, M., Zen, K., Takahashi, T., Azuma, A., Tateishi, K., Nomura, T., Hayashi, H., Nakajima, N., Okigaki, M., and Matsubara, H. 2005. Carbon dioxide-rich water bathing enhances collateral blood flow in ischemic hindlimb via mobilization of endothelial progenitor cells and activation of NO-cGMP system. Circulation, 111: 1523-1529.

Ito, T., Moore, J.I., and Koss, M.C. 1989. Topical application of $\mathrm{CO}_{2}$ increases skin blood flow. J. Invest. Dermatol. 93: 259-262.

Izumi, Y., Yamaguchi, T., Yamazaki, T., Yamashita, N., Nakamura, Y., Shiota, M., Tanaka, M., Sano, S., Osada-Oka, M., Shimada, K., Wanibuchi, H., Miura, K., Yoshiyama, M., and Iwao, H. 2015. Percutaneous carbon dioxide treatment using a gas mist generator enhances the 
collateral blood flow in the ischemic hindlimb. J. Atheroscler. Thromb. 22: 38-51.

Kehler, D.S., Dhalla, N.S., and Duhamel, T.A. 2013. Biochemical mechanisms of exerciseinduced angiogenesis. In Biochemical Basis and Therapeutic Implications of Angiogenesis. Edited by J.L. Mehta and N.S. Dhalla. Springer Science+Business Media, LLC, New York, pp. 181-206.

Krishna, S.M., Moxon, J.V., and Golledge, J. 2015. A review of the pathophysiology and potential biomarkers for peripheral artery disease. Int. J. Mol. Sci. 16: 11294-11322.

Li, W.W., Li, V.W., Casey, R., Tsakayannis, D., Kruger, E.A., Lee, A., Sun, Y.-L., Bonar, C.A., and Cornelius S. 1998. Clinical trials of angiogenesis-based therapies: Overview and new guiding principles. In Angiogenesis: Models, modulators, and clinical applications. Edited by M. Maragoudakis. Plenum Press, New York, N.Y., pp. 475-492.

Limbourg, A., Korff, T., Napp, L.C., Schaper, W., Drexler, H., and Limbourg, F.L. 2009. Evaluation of postnatal arteriogenesis and angiogenesis in a mouse model of hind-limb ischemia. Nat. Protoc. 4: 1737-1746.

Lloyd, P.G., Yang, H.T., and Terjung, R.L. 2001. Arteriogenesis and angiogenesis in rat ischemic hindlimb: role of nitric oxide. Am. J. Physiol. Heart Circ. Physiol. 281: H2528H2538.

Milkiewicz, M., Hudlicka, O., Brown, M.D., and Silgram, H. 2005. Nitric oxide, VEGF, and VEGFR-2: interactions in activity-induced angiogenesis in rat skeletal muscle. Am. J. Physiol. Heart Circ. Physiol. 289: H336-H343.

Nishimura, N., Sugenoya, J., Matsumoto, T., Kato, M., Sakakibara, H., Nishiyama, T., Inukai, Y., Okagawa, T., and Ogata, A. 2002. Effects of repeated carbon dioxide-rich water bathing on core temperature, cutaneous blood flow and thermal sensation. Eur. J. Appl. Physiol. 
87:337-342.

Norgren, L., Hiatt, W.R., Dormandy, J.A., Nehler, M.R., Harris, K.A., Fowkes, F.G., and Rutherford, R.B. 2007. Inter-society consensus for the management of peripheral artery disease. Int. Angiol. 26: 81-157.

Olfert, I.M., Baum, O., Hellsten, Y., and Egginton, S. 2016. Advances and challenges in skeletal muscle angiogenesis. Am. J. Physiol. Heart Circ. Physiol. 310: H326-H336.

Pagourelias, E.D., Zorou, P.G., Tsaligopoulos, M., Athyros, V.G., Karagiannis, A,, and Efthimiadis, G.K. 2011. Carbon dioxide balneotherapy and cardiovascular disease. Int. J. Biometeorol. 55: 657-663.

Potente, M., Gerhardt, H., and Carmeliet, P. 2011. Basic and therapeutic aspects of angiogenesis. Cell, 146: 873-887.

Raval, Z., and Losardo, D.W. 2013. Cell therapy of peripheral arterial disease: from experimental findings to clinical trials. Circ. Res. 112: 1288-1302.

Reddy, A.K., Madala, S., Jones, A.D., Caro, W.A., Eberth, J.F., Pham, T.T., Taffet, G.E., and Hartley, C.J. 2009. Multi-channel pulsed doppler signal processing for vascular measurements in mice. Ultrasound Med. Biol. 35: 2042-2054.

Sato, M., Kanikowska, D., Iwase, S., Nishimura, N., Shimizu, Y., Belin de Chantemele, E., Matsumoto, T., Inukai, Y., Taniguchi, Y., Ogata, A., and Sugenoya, J. 2009. Effects of immersion in water containing high concentrations of $\mathrm{CO}_{2}\left(\mathrm{CO}_{2}\right.$-water $)$ at thermoneutral on thermoregulation and heart rate variability in humans. Int. J. Biometeorol. 53: 25-30.

Schirmer, S.H., Millenaar, D.N., Werner, C., Schuh, L., Degen, A., Bettink, S.I., Lipp, P., van Rooijen, N., Meyer, T., Bohm, M., and Laufs, U. 2015. Exercise promotes collateral artery growth mediated by monocytic nitric oxide. Arterioscler. Thromb. Vasc. Biol. 35: 1862-1871. 
Serrano Hernando, F.J., and Martin Conejero, A. 2007. Peripheral artery disease: Pathophysiology, diagnosis and treatment. Rev. Esp. Cardiol. 60: 969-982.

Shao, Q., Ren, B., Saini, H.K., Netticadan, T., Takeda, N., and Dhalla, N.S. 2005. Sarcoplasmic reticulum $\mathrm{Ca}^{2+}$-transport and gene expression in congestive heart failure are modified by imidapril treatment. Am. J. Physiol. Heart Circ. Physiol. 288: H1674-H1682.

Singla, S., and Mehta, J.L. 2013. Trials of angiogenesis therapy in patients with ischemic heart disease. In Biochemical Basis and Therapeutic Implications of Angiogenesis. Edited by J.L. Mehta and N.S. Dhalla. Springer Science+Business Media, LLC, New York. pp. 313-334.

Tappia, P., Dent, M.R., and Dhalla, N.S. 2006. Oxidative stress and redox regulation of phospholipase D in myocardial disease. Free Rad. Biol. 41: 349-361.

Yang, Z., von Ballmoos, M.W., Diehm, N., Baumgartner, I., Kalka, C., Di Santo, S. 2009. Call for a reference model of chronic hind limb ischemia to investigate therapeutic angiogenesis. Vascul. Pharmacol. 51: 268-274. 


\section{Legends to Figures}

Figure 1. Concentration of $\mathrm{CO}_{2}$ in water-bath during and after mixing (A) and the experimental design of study (B). Assessment of each animal immediately after the ligation of femoral artery did not show any blood flow in the hind limb. It should be noted that animals in both control and ischemic control groups were not subjected to water-bath whereas rats in ischemic $+\mathrm{CO}_{2}$ group and ischemic $-\mathrm{CO}_{2}$ group were subjected to water-bath with or without $\mathrm{CO}_{2}$ mixing, respectively.

Figure 2. Effect of $\mathrm{CO}_{2}$ water-bath therapy on peak blood flow (A), minimal blood flow (B), and mean blood flow (C) in the rat hind leg skeletal muscle. Normal rats with 2 weeks femoral artery ligation were subjected to water-bath at $37^{\circ} \mathrm{C}$ with or without $\mathrm{CO}_{2}$ for 4 weeks and were labelled as ischemic $+\mathrm{CO}_{2}$ and ischemic $-\mathrm{CO}_{2}$ groups, respectively. Normal control rats and ischemic control rats were not subjected to water-bath. Values are mean $\pm \mathrm{SE}$ of 6 animals in each group. ${ }^{*}-P<0.05$ vs control, ${ }_{-}^{\#} P<0.05$ vs ischemic $-\mathrm{CO}_{2}$ group. Since the values for each parameter of blood flow in ischemic control group were not significantly $(P>0.05)$ different from the respective value in the control group, the data for the ischemic control group are not shown in this figure. It should be noted that both control group and ischemic control group were not subjected to water-bath treatment.

Figure 3. Representative histological alterations in the skeletal muscle sections for control (A), ischemic control (B), ischemic $-\mathrm{CO}_{2}$ (C) and ischemic $+\mathrm{CO}_{2}$ (D) groups. Quantitative analysis of the number of blood vessels per tissue section in each group is shown in Panel $\mathrm{E}$ and the values are mean $\pm \mathrm{SE}$ of 6 animals in each group. * $P<0.05 v s$ control, ${ }^{\#}-P<0.05$ vs ischemic $+\mathrm{CO}_{2}$ group. It should be noted that animals 
in both control and ischemic control groups were not subjected to water-bath whereas those in ischemic $+\mathrm{CO}_{2}$ group and ischemic $-\mathrm{CO}_{2}$ group were subjected to waterbath with or without $\mathrm{CO}_{2}$ mixing, respectively.

Figure 4. Plasma VEGF, NO, TNF- $\alpha$ and MDA levels with or without $\mathrm{CO}_{2}$ water-bath treatment in rats subjected to femoral artery ligation. Each value is a mean \pm SE of 6 animals in each group. VEGF - vascular endothelial growth factor, NO - nitric oxide, TNF- $\alpha$ - tissue necrosis factor- $\alpha$, and MDA - malondialdhyde. ${ }^{*}-P<0.05$ vs control, ${ }^{\#}-P<0.05 v s$ ischemic $+\mathrm{CO}_{2}$ group. Since the values for VEGF, NO, TNF- $\alpha$, and MDA levels in ischemic control group were not significantly $(P>0.05)$ different from the respective values in control group, the data for the ischemic control group are not shown in this figure. Animals in both control and ischemic control groups were not subject to water-bath.

Figure 5. Proposed mechanisms of increase in blood flow in the ischemic limb due to $\mathrm{CO}_{2}$ water-bath therapy through the development of angiogenesis as well as modification of redox-sensitive signal transduction in the skeletal muscle. It should be mentioned that redox state represents a balance between the formation of oxyradicals and the removal of oxyradicals in the tissue. 
Table 1. Heart rate, R-R interval and plasma creatine kinase level with or without $\mathrm{CO}_{2}$ waterbath treatment in rats subjected to femoral artery ligation.

\begin{tabular}{lccc}
\hline & Control & Ischemic $-\mathrm{CO}_{2}$ & Ischemic $+\mathrm{CO}_{2}$ \\
\hline Body wt $(g)$ & $541 \pm 11$ & $518 \pm 13$ & $534 \pm 13$ \\
Heart rate (beats/min) & $316 \pm 5$ & $322 \pm 8$ & $327 \pm 11$ \\
R-R interval (msec) & $186 \pm 4$ & $193 \pm 7$ & $192 \pm 7$ \\
Creatine kinase (U/L) & $585 \pm 99$ & $543 \pm 92$ & $466 \pm 75$ \\
\hline
\end{tabular}

Each value is a mean \pm SE of 6 animals in each group. Since the values for each parameter for the ischemic control group were not significantly $(P>0.05)$ different from the respective values for the control group, the data for the ischemic control group are not shown in this table. It is pointed out that both control and ischemic control animals were not subjected to water-bath. 
Table 2. Plasma lipids and glucose levels with or without 4 weeks $\mathrm{CO}_{2}$ water-bath treatment in rats subjected to femoral artery ligation.

\begin{tabular}{lccc}
\hline & Control & Ischemic $-\mathrm{CO}_{2}$ & Ischemic $+\mathrm{CO}_{2}$ \\
\hline $\begin{array}{l}\text { Total cholesterol } \\
(\mathrm{mmol} / \mathrm{L})\end{array}$ & $1.62 \pm 0.11$ & $1.50 \pm 0.14$ & $1.70 \pm 0.13$ \\
$\begin{array}{l}\text { High density lipoprotein } \\
(\mathrm{mmol} / \mathrm{L})\end{array}$ & $0.93 \pm 0.08$ & $1.01 \pm 0.12$ & $1.12 \pm 0.14$ \\
$\begin{array}{l}\text { Triglycerides }(\mathrm{mmol} / \mathrm{L}) \\
\text { Glucose }(\mathrm{mmol} / \mathrm{L})\end{array}$ & $2.63 \pm 0.37$ & $1.41 \pm 0.18^{*}$ & $1.76 \pm 0.77$ \\
\hline
\end{tabular}

Each value is a mean \pm SE of 6 animals in each group. $* P<0.05$ compared with control value. Since the values for each parameter for the ischemic control group were not significantly $(P>0.05)$ different from the respective values for the control group, the data for the ischemic control group are not shown in this table. Both control and ischemic control animals were not subjected to water-bath. 


\section{A. $\mathrm{CO}_{2}$ Concentration}

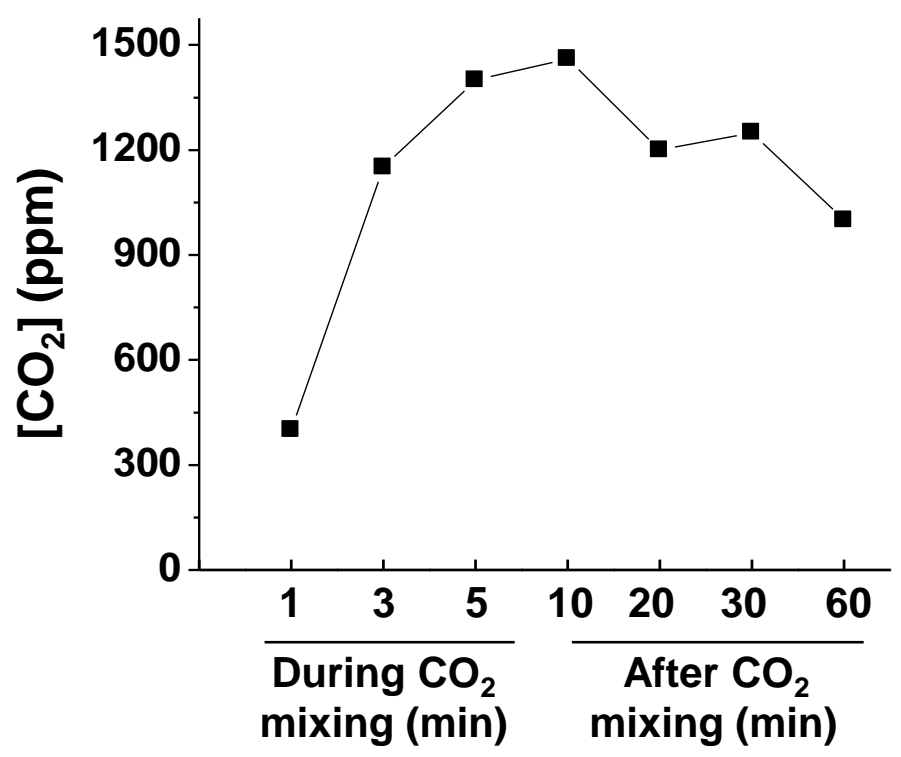

\section{B. Experimental Design}

\section{Control}

\begin{tabular}{|c|c|}
\hline $\begin{array}{c}\text { Left femoral } \\
\text { artery ligation }\end{array}$ & Ischemic control \\
\hline
\end{tabular}

Left femoral artery ligation $37^{\circ} \mathrm{C}$ water bath therapy without

$\mathrm{CO}_{2}$ (ischemic - $\mathrm{CO}_{2}$ )
Left femoral artery ligation $37^{\circ} \mathrm{C}$ water bath therapy with

$\mathrm{CO}_{2}$ (ischemic $+\mathrm{CO}_{2}$ )

2 Weeks

4 Weeks 
A. Peak blood flow
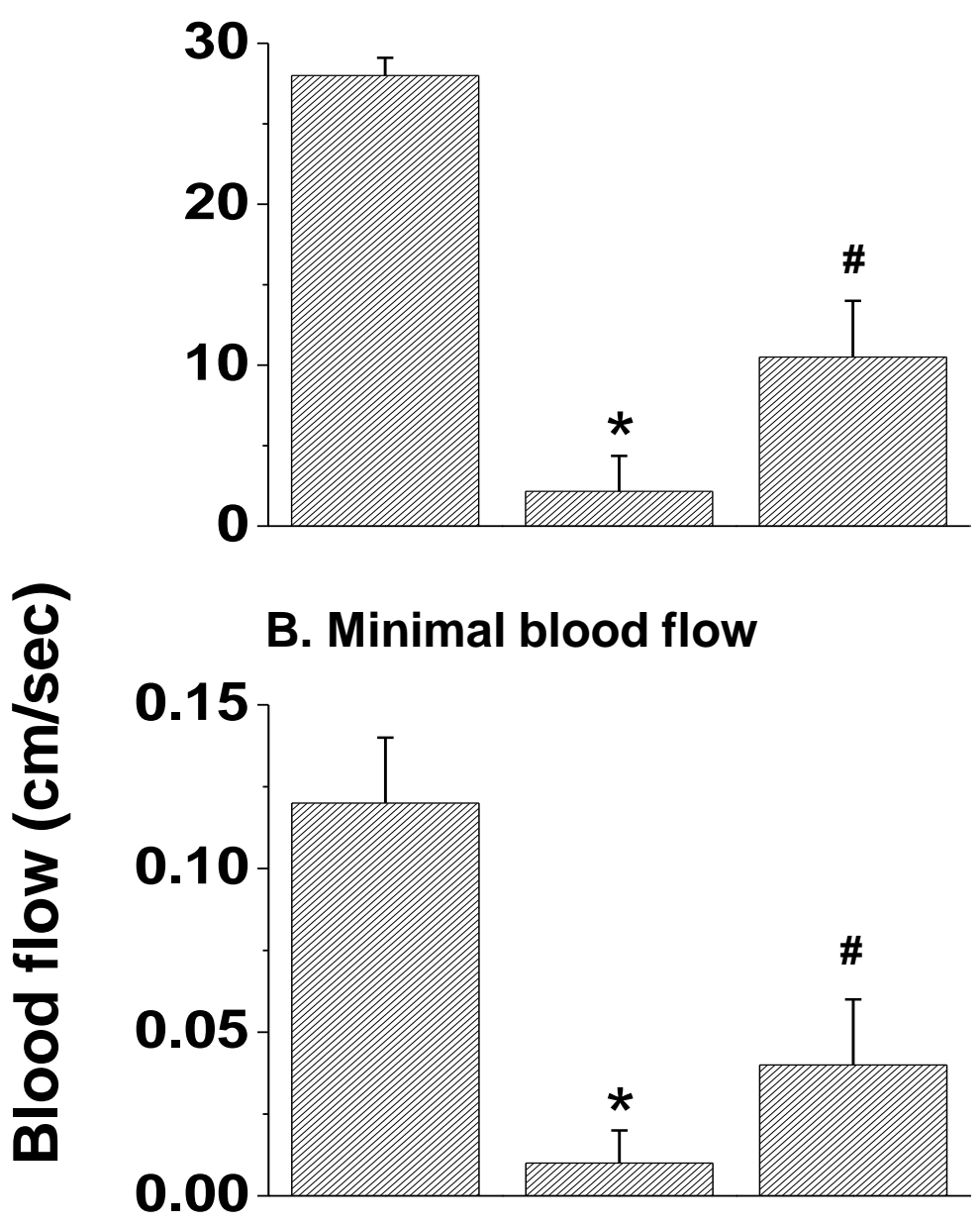

C. Mean blood flow

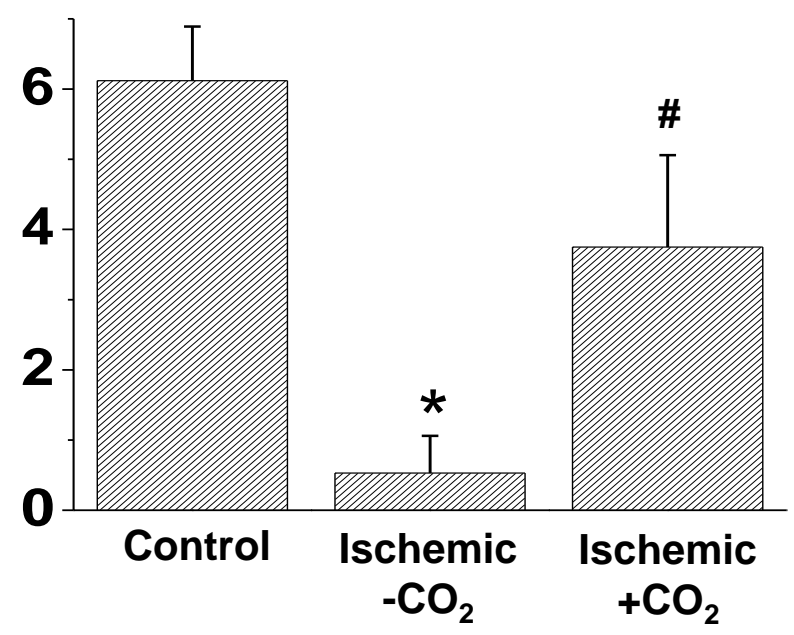




\section{A. Control}

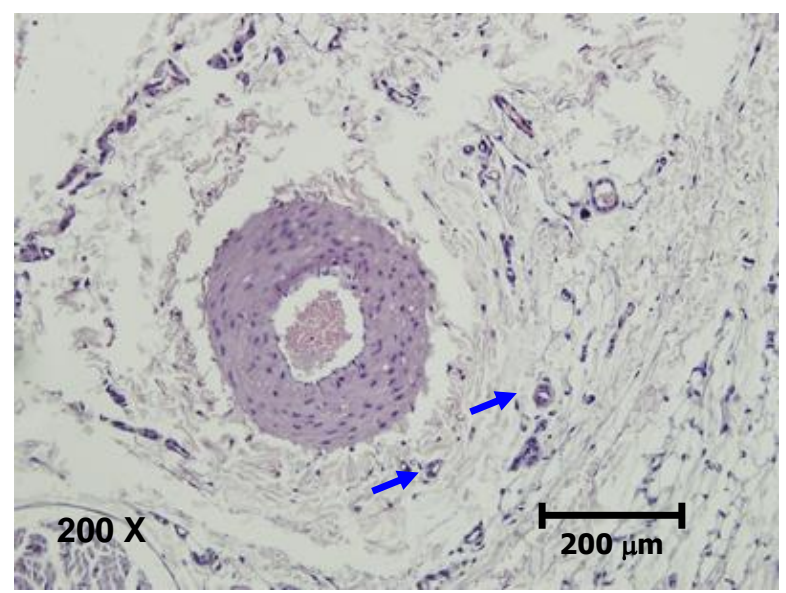

\section{B. Ischemic Control}

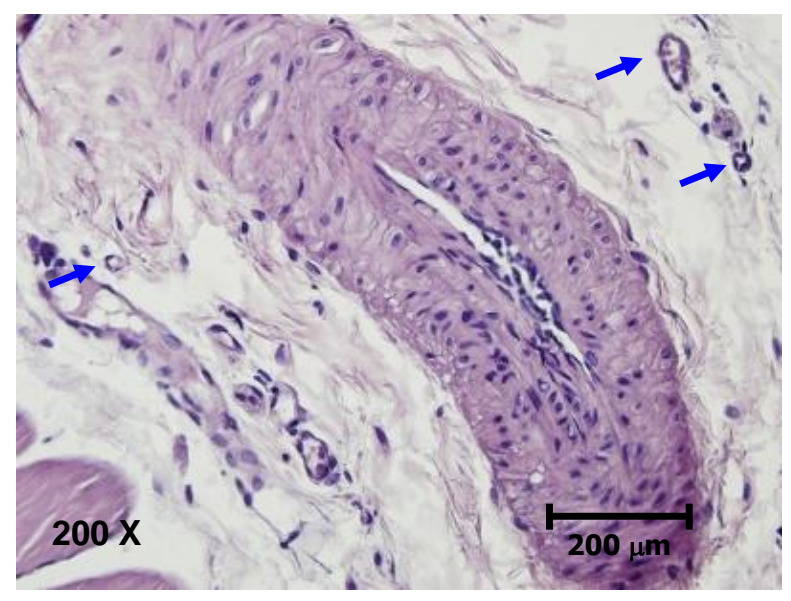

C. Ischemic $-\mathrm{CO}_{2}$

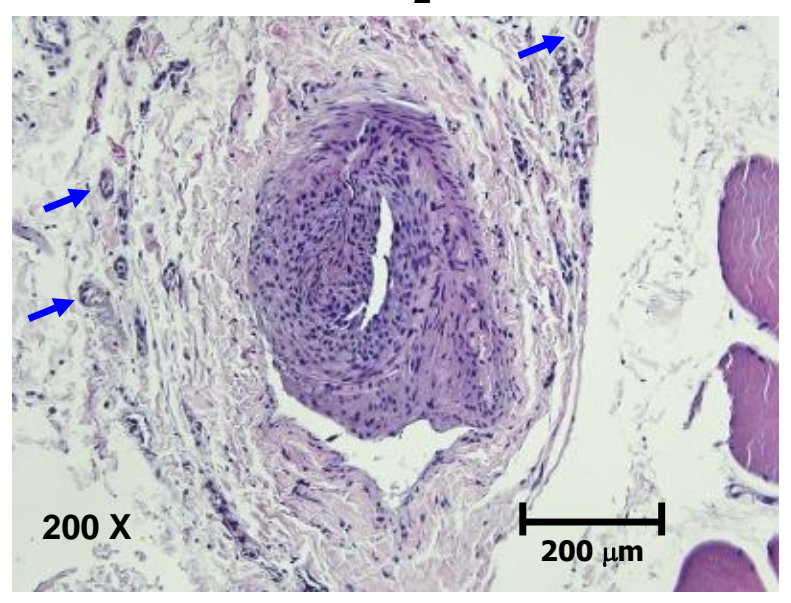

D. Ischemic $+\mathrm{CO}_{2}$

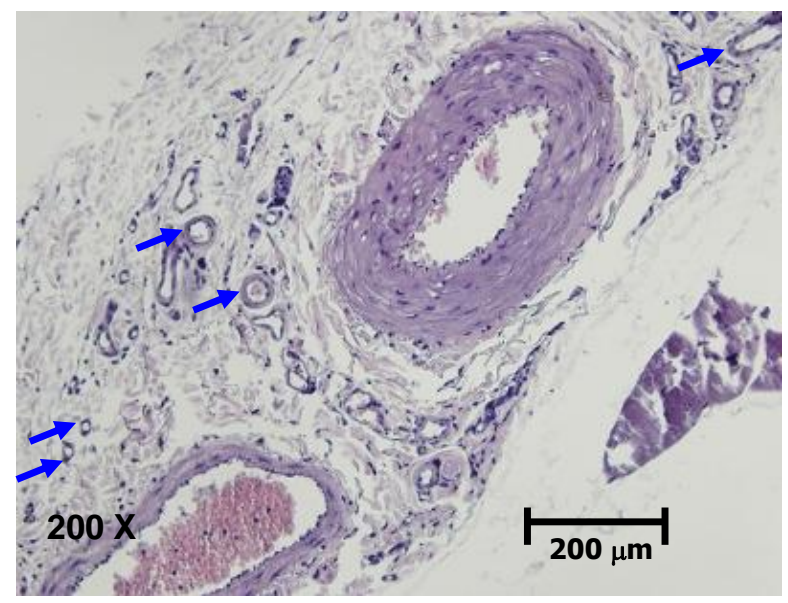

\section{E. Blood vessel count}

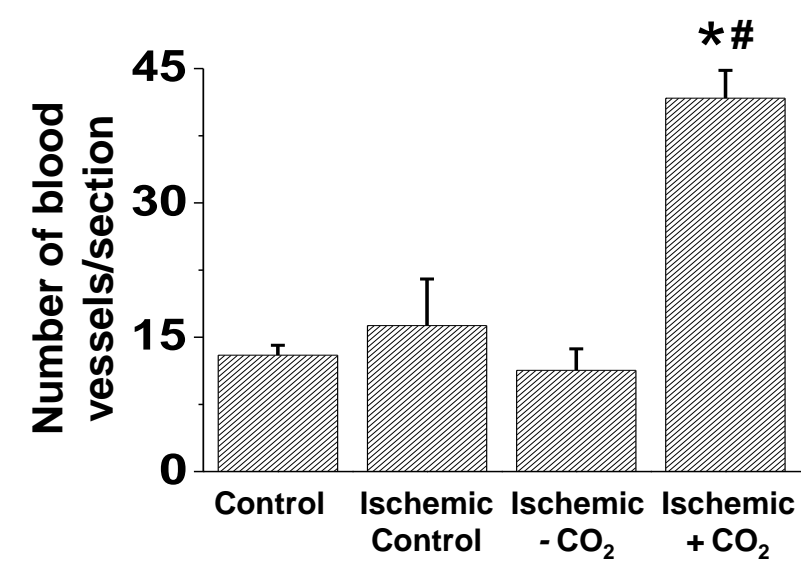

https://mc06.manuscriptcentral.com/cjpp-pubs Xu et al - Figure 3 


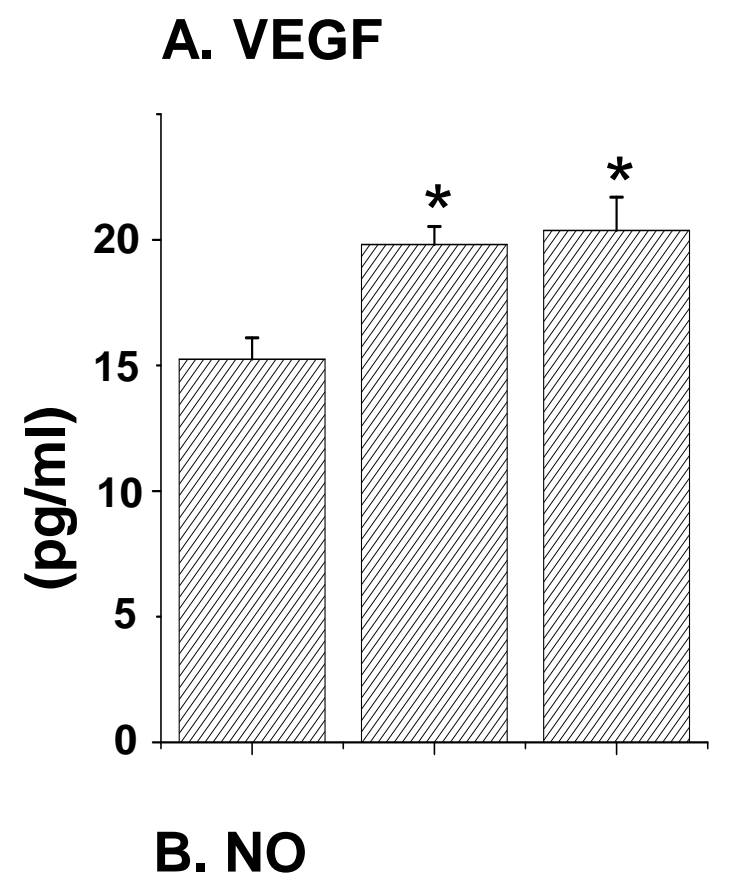

\section{TNFa}
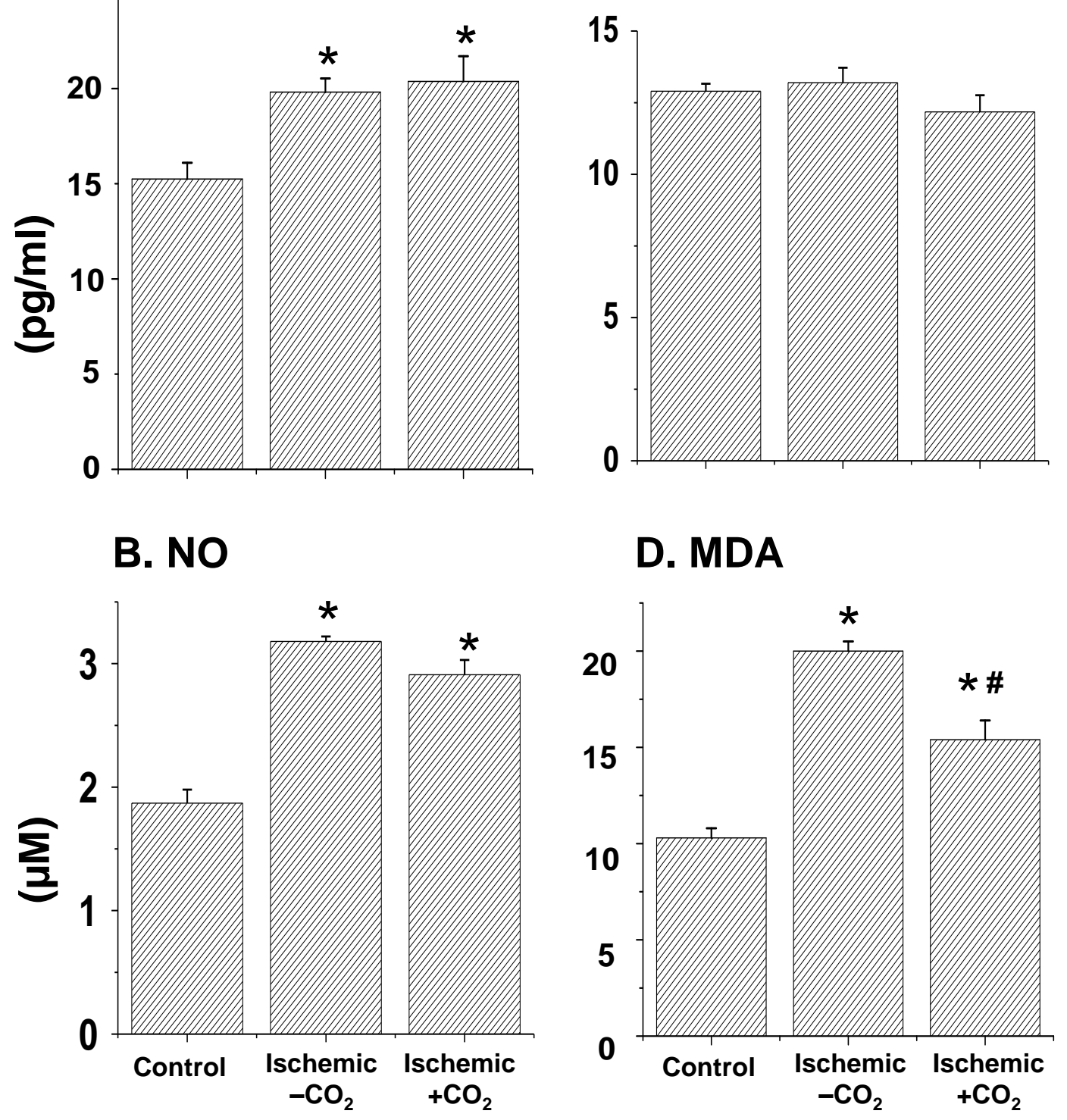


\section{$\mathrm{CO}_{2}$ Water Bath Therapy}

$\downarrow$

Exposure of Skeletal Muscle to $\mathrm{CO}_{2}$

$\downarrow$

Modification of Redox-sensitive Signal Transduction

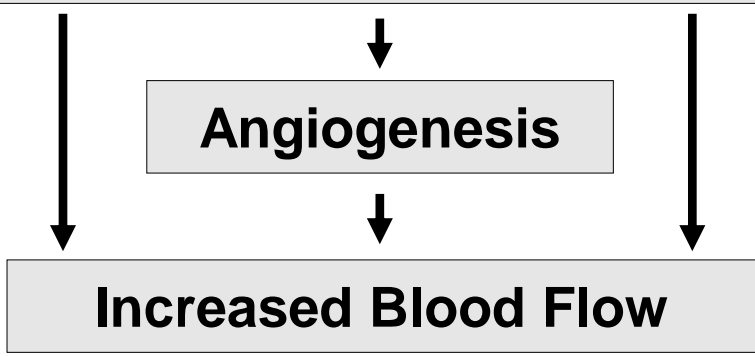

Xu et al - Figure 5 